\title{
USGS EROS Interdisciplinary Science Collaboration with BRD, GD, GIO, and WRD
}
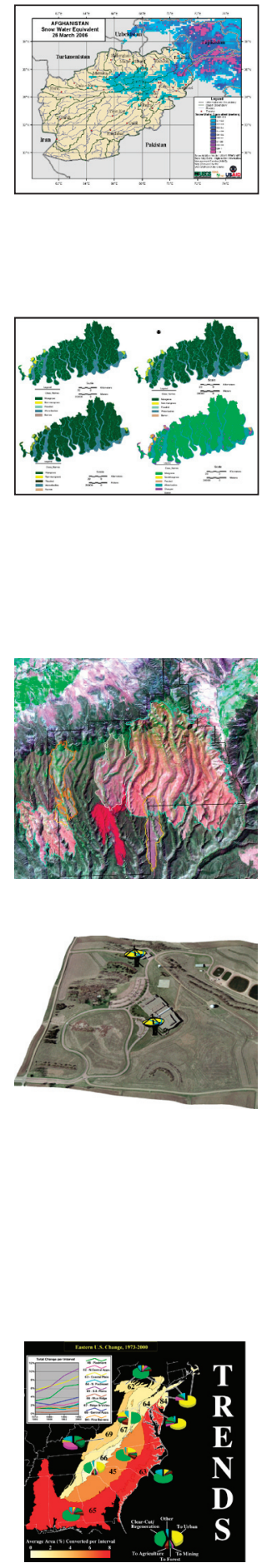

\section{Afghanistan Reconstruction Project}

Provides geospatial data management services, as well as participation in modeling and monitoring studies of snow pack, irrigation, and flood hazards.

*USAID Afghanistan, WRD, GD

\section{Asian Tsunami \&} Mangrove Forest

Monitors deforestation and degradation of mangrove forests from 1970 to 2005 , investigates the impacts of tsunami on mangrove forests, and identifies the role of mangrove forests in saving lives and protecting property.

*BRD, Colorado State University

\section{Burn Severity Mapping}

Monitors burn severity and vegetation recovery, conducts research on post-fire analysis and monitoring, and studies the link between burn severity and landslide hazards.

*BRD, GD, NPS

\section{GOES Backup for WRD National Water Information System (NWIS)}

USGS supports WRD's GOES Data Collection System (DCS) by installing a Direct Readout Ground Station which will receive data directly from the GOES satellites. This will provide an alternate source of GOES data in case of failure at the Wallops Island facility. *WRD

\section{Land Cover Trends}

Conducts a national analysis of the rates, causes, and consequences of land use and land cover change.

* BRD, NASA, EPA, South Dakota State University, State University of New York

- Environmental Science and Forestry, University of Southern Mississippi
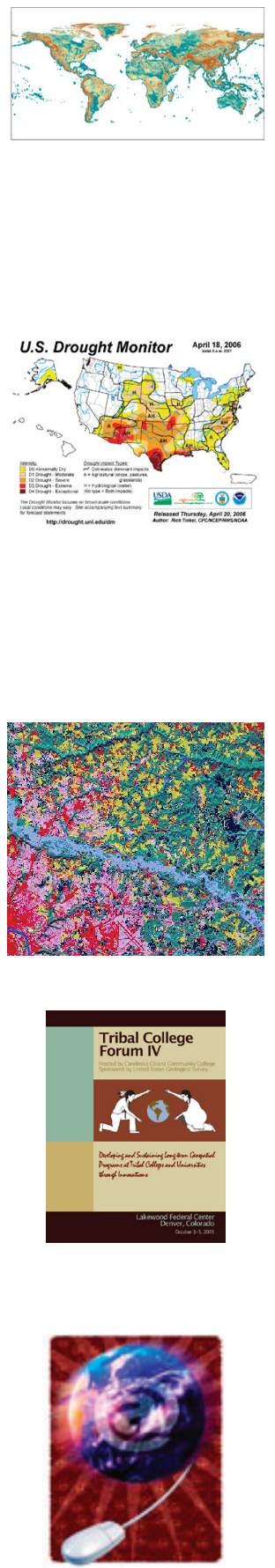

\section{Wide Area Networking}

Member of the GeoNet3 Team that manages the USGS WAN. Actively involved in the planning and implementation of the integration of the USGS backbone network into the DOI Enterprise Secure Network (ESN). *GIO 

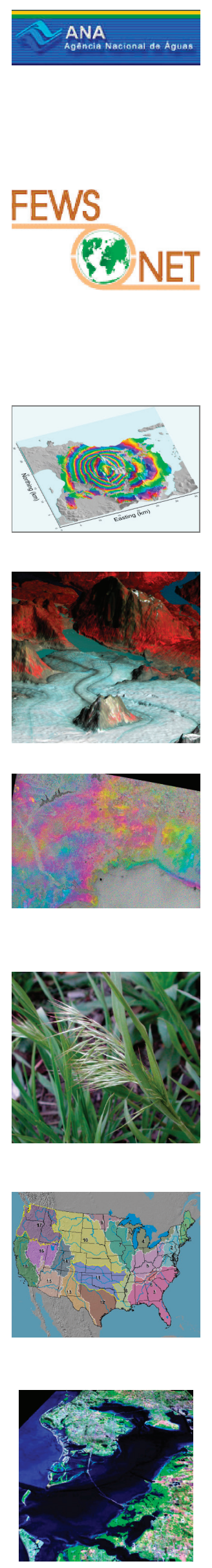

\section{Modernization of Hydrological} Network in Brazil

Identifies items of technical cooperation and proposal preparation.

*GD, WRD, WMO, World Bank

\section{Famine Early Warning (FEWS)}

Coordinates FEWS NET climate monitoring to enhance the flow of information between regional and local levels in Africa, Central America and Afghanistan.

*WRD

\section{Study of Volcanoes with InSAR}

Volcano studies with InSAR Imagery. *GD, NASA

\section{Global Land Ice Measurements from Space (GLIMS)}

Maps the location and spatial extent of land-based glaciers, and monitors changes in their areal extent.

*GD, various international collaborators

\section{Study of Vegetation and Flood Dynamics with SAR Imagery}

Uses SAR data and InSAR data to map vegetation and water levels over coastal regions.

*BRD

\section{Invasive Species:}

\section{A U.S.-China Case Study}

Investigates potential distribution in the U.S. of selected invasive plants from China through use of GIS, remote sensing, and ecological modeling.

*BRD

\section{Watershed Boundaries Dataset}

Provides EDNA data, GIS procedures, and consultation to State and Federal collaborators to enable them to produce the Watershed Boundaries Dataset.

*WRD

\section{Tampa Bay Integrated Science Study}

Studies anthropogenic effects on the ecology of the Tampa Bay estuary.

*GD, WRD, BRD
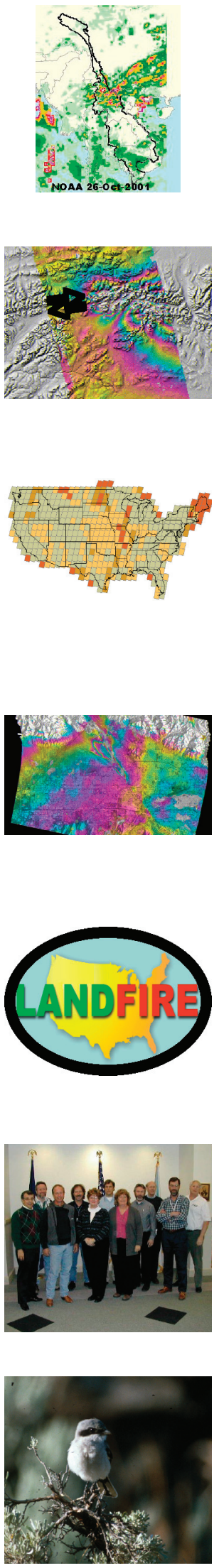

Flood Information System for Asian Countries

Improves river forecasting for the Mekong River Commission and technical cooperation with foreign counterparts.

*WRD, NOAA

\section{Study of Great Earthquakes with InSAR}

Detects and maps precursory inter-seismic or pre-seismic strain accumulation before large earthquakes. *GD

\section{Multi-Resolution Land Characterization 2001}

A consortium of Federal agencies developing a Landsat database for the United States.

*BRD, GD, BLM, EPA, NASA, NOAA, NPS, NRCS, USFWS, USFS

\section{Study of Land Subsidence}

Maps land subsidence and aquifer systems and associated building movements with InSAR imagery both national and international.

*WRD

\section{LANDFIRE}

Applies Landsat data to map and model vegetation composition and structure, and characterize fire fuels and risks nationwide.

*BRD, USFS, TNC

\section{USGS Advisory Group on Remote Sensing}

Provides advice and guidance to the Land Remote Sensing Program (LRS)

*GD, BRD, WRD

\section{Breeding Birds and Habitat Change in the Intermountain West}

Compares a 30-year analysis of habitat change interpreted from Landsat data to breeding bird population statistics from the Breeding Bird Survey (BBS) database to identify the extent land use change affects intermountain western bird populations.

*BRD 

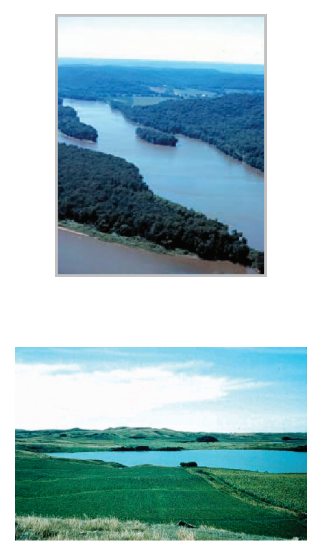

\section{Remote Sensing Collaboration between EROS and UMESC}

Co-location of a USGS EROS scientist with the Upper Midwest Environmental Science Center (UMESC) in LaCrosse, Wisconsin.

*BRD

\section{Role of Wetlands in Greenhouse Gas Storage}

Evaluates differences in carbon storage among various wetland types and how carbon production varies with climate change.

*WRD, BRD, GD, USDA-ARS

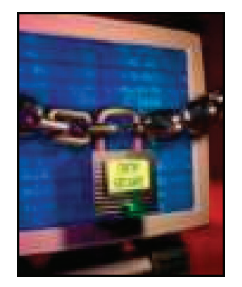

\section{IT Security}

Participates in the Technology Security Committee, the IT Security Operation Team, and the Computer Security Incident Response Team.

*GIO

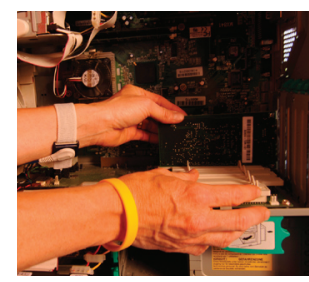

\section{IT Service Desk}

Member of review team for the implementation of this activity in Denver.

*GIO

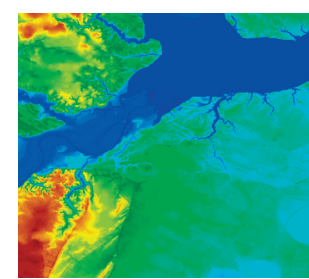

\section{Mapping of Land Vulnerable to Sea-Level Rise}

Development and dissemination of maps of land at risk from the effects sea-level rise. Products are based on high-resolution coastal lidar data collections.

*GD, BRD

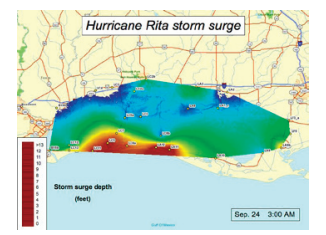

\section{Hurricane Rita Storm Surge Mapping}

Visualization of storm surge propagation through time, derived from data collected by in-situ water level sensor network.

*WRD

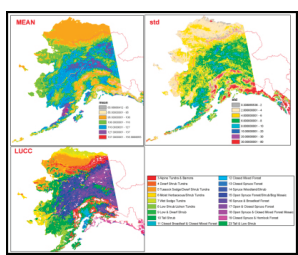

Yukon River Basin and the IPY: Integrated Simulation Modeling, Remote Sensing, and Discipline

\section{Studies}

Integrates numerous projects to achieve an understanding of ecosystem changes and carbon budgets in an area showing profound ecological changes as a result of changing climate. Climate feedbacks, permafrost thawing, increasing fires, coastal impacts, and human livelihoods are studied.

*WRD, GD, BRD, LTER sites, Alaska Science Center, Alaska Science Center

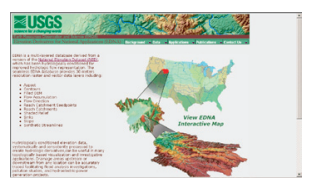

\section{Water Modeling with EDNA}

Provides Elevation Derivatives for National Applications (EDNA) topographic layers in support of WRD's modeling and NAWQA efforts, and in the development of Watersheds Boundary Dataset.

*WRD

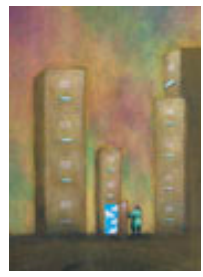

\section{Data Storage}

Leads and represents USGS on the DOI Storage Investigation Team. Seeking Department level opportunities for data storage initiatives.

*GIO

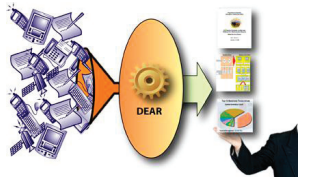

\section{Enterprise Architecture}

EROS serves as USGS representative for DOI Enterprise Architecture activities including Department Enterprise Architecture Repository (DEAR) and the Bureau Enterprise Architecture Repository (BEAR). Also involved with Bureau efforts with Geospatial Line of Business effort from OMB.

*GIO

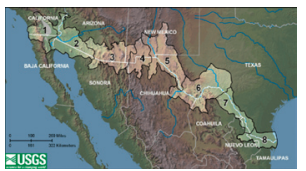

\section{Texas Border Health}

http://borderhealth.cr.usgs.gov

The major issues surrounding the U.S.-Mexico border involve economics and population growth that present challenges to environmental management and natural resource planning. This site provides the ability to monitor trends and analyze the stresses to the environment, through binationally integrated baseline.

*BRD, GD, WRD, NMD 


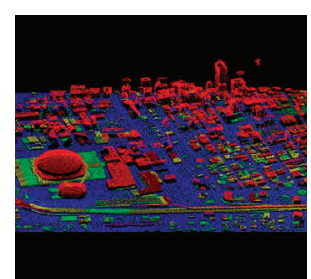

\section{Center for LIDAR Information Coordination and Knowledge (CLICK)}

Provides data collection coordination, processing and analysis information, and unfiltered raw data access for scientific research.

*BRD, WRD, GD, USFS, NRCS, FEMA

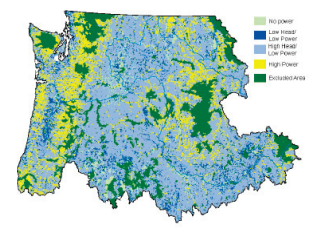

\section{Low-Head Dam National Power} Potential Assessment

Conducts a National analysis of lowhead dam power potential using the Elevation Derivatives for National Applications (EDNA) database and climate data.

*WRD
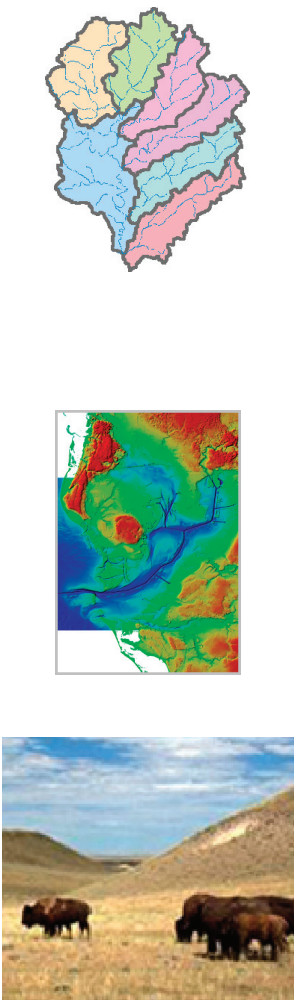

\section{NativeView}

Develops prototype applications based on scientific and traditional descriptors of tribal landscapes.

*WRD, BRD, GD

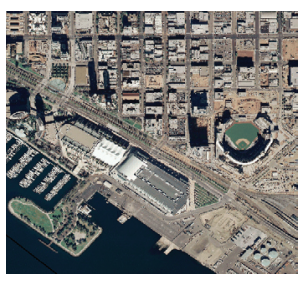

\section{The Seamless Server}

Distributes map services and online downloads of orthoimagery, elevation, landcover, and other USGS data sets in support of The National Map and Geospatial One Stop.

*GIO

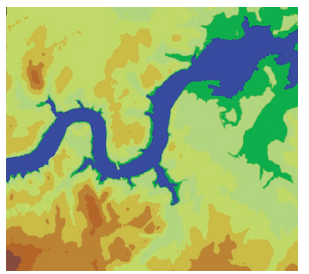

\section{Inundation Mapping}

Develops and tests automated GIS methods for deriving inundation patterns from digital elevation models, with validation against conventional manual methods.

*WRD

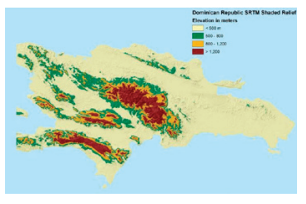

\section{Geoservers and Spatial Data for IABIN Development Grant}

Develop infrastructure and provide remote sensing and SRTM 30m derived products for Central America and the Caribbean. Supported by the World Bank.

*BRD, TNC, NASA, 14 agencies in Central America, AID, WB

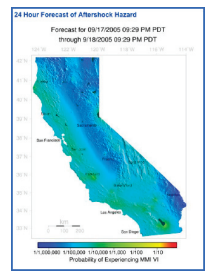

\section{Southern California Hazards Demonstration Project}

USGS EROS Chief Scientist is a member of planning team.

*All USGS

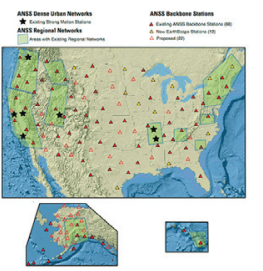

\section{ANSS - Advanced National Seismic System}

USGS EROS is the site for one of a nationwide network of over 7000 earthquake sensor systems that will provide real-time earthquake information for emergency response personnel, engineers, and scientists. *GD

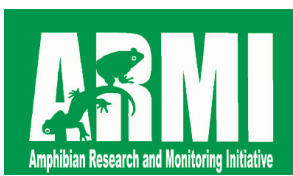

\section{Amphibian Research and Monitoring Initiative (ARMI)}

Provides expertise in remote sensing, GIS, geostatistics, environmental modeling, and geographic integration across spatial scales.

*WRD, BRD, and non-USGS ARMI cooperators 